\title{
Natural Antioxidants for the Prevention of Atherosclerosis
}

\author{
Rudina M. Odeh, Pharm.D., and Laura A. Cornish, Pharm.D. \\ Hypercholesterolemia, cigarette smoking, hypertension, and obesity are \\ known contributing risk factors for the development of atherosclerotic \\ coronary artery disease (CAD). However, they account for only half of all \\ cases of $C A D$, and the complete pathologic process underlying atherosclerosis \\ remains unknown. Growing evidence suggests that oxidative modification of \\ low-density lipoprotein (LDL) may be of particular importance in the \\ pathogenesis. Oxidized LDL exhibits proatherogenic effects. Therefore, \\ current research has focused on inhibiting the oxidation of LDL as a means of \\ inhibiting the atherosclerotic process. One such approach is to enhance the \\ endogenous antioxidant defense systems within the LDL particle with \\ lipophilic antioxidants such as $\alpha$-tocopherol and $\beta$-carotene, or by \\ supplementing the aqueous-phase antioxidant capacity with asçorbic acid. \\ Observational data suggest a protective effect of antioxidant supplementation \\ on the incidence of CAD; however, specific doses cannot be recommended \\ since the data are inconclusive.
}

(Pharmacotherapy 1995;15(5):648-659)

\section{OUTLINE}

Hypothesis of Oxidative Modification

Vitamin E

$\beta$-Carotene

Vitamin C

Selenium

Recommendations and Conclusions

Acute myocardial infarction is a leading contributor to premature death among adults in Western civilization. ${ }^{1,2}$ Its incidence in the United States has been estimated at 1.5 million cases annually (1:160 persons), with more than 500,000 deaths and approximately 750,000 hospitalizations a year. ${ }^{3-5}$ An estimated 1.25 million people experienced a myocardial infarction in 1993, and nearly 500,000 are thought to have died. ${ }^{2}$

It is well known that the primary underlying cause of acute myocardial infarction is atherosclerotic coronary artery disease (CAD). Approximately 5.4 million individuals are

From the Department of Pharmacy Services, University of Michigan Medical Center and College of Pharmacy, Ann Arbor, Michigan (both authors).

Address reprint requests to Rudina M. Odeh, Pharm.D., University of Michigan Medical Center, 1500 East Medical Center Drive, B2D301/Box 0008, Ann Arbor, MI 48109. diagnosed with CAD annually, which collectively results in direct health care costs exceeding $\$ 8$ billion each year. ${ }^{6}$ However, the incidence of death due to CAD has declined substantially over the past 25 years. ${ }^{6}$ This decline may be attributed partly to a reduction of risk factors such as cigarette smoking, hypertension, obesity, and hypercholesterolemia. These factors account for nearly half of all cases of CAD, but the complete pathologic process underlying atherosclerosis remains unknown. ${ }^{7}$

Scientific evidence strongly suggests that oxidative modification of the low-density lipoprotein (LDL) particle may play an important causative role in the development of atherosclerosis. ${ }^{8}$ This theory, known as the oxidative modification hypothesis, has led to the development of many clinical and epidemiologic trials to examine the effect of various natural antioxidants (vitamin $\mathrm{E}, \beta$-carotene, vitamin $\mathrm{C}$, selenium) on the disease.

\section{Hypothesis of Oxidative Modification}

In vitro studies show that native (unmodified) LDL is unlikely to contribute to the development of atherosclerotic lesions. The lipoprotein may be transformed into an atherogenic agent 
through several mechanisms, including acetylation, ${ }^{9}$ nonenzymatic glycation, ${ }^{10}$ and oxidation. ${ }^{11}$ Evidence suggests that the oxidative modification of LDL may be of particular importance. ${ }^{9,12,13}$

Figure 1 outlines the oxidative modification hypothesis and depicts the potential proatherogenic effects of oxidized LDL. ${ }^{14}$ The initial event is the accumulation of cholesterolloaded foam cells within the subendothelial space of the arteries. These foam cells originate from monocyte-derived tissue macrophages, which internalize extracellular lipids such as LDL. Once formed, foam cells have the potential to accumulate within the subendothelial space to form a fatty streak. The fatty streak is the earliest manifestation of the atherosclerotic lesion. ${ }^{15 .} 16$ It can develop during childhood (first 2 decades of life), but during this period it is usually clinically silent. As the foam cells continue to accumulate, usually during the third and fourth decades, the fatty streak increases in size to form an overt atherosclerotic plaque. ${ }^{17}$

The classic LDL receptor (apoprotein $B$ /apoprotein $E$ receptor) is expressed on the tissue macrophage and mediates the uptake of native LDL. However, the native LDL receptor is subject to feedback inhibition by cellular cholesterol content. The amount of native LDL taken up by the classic LDL receptor pathway is

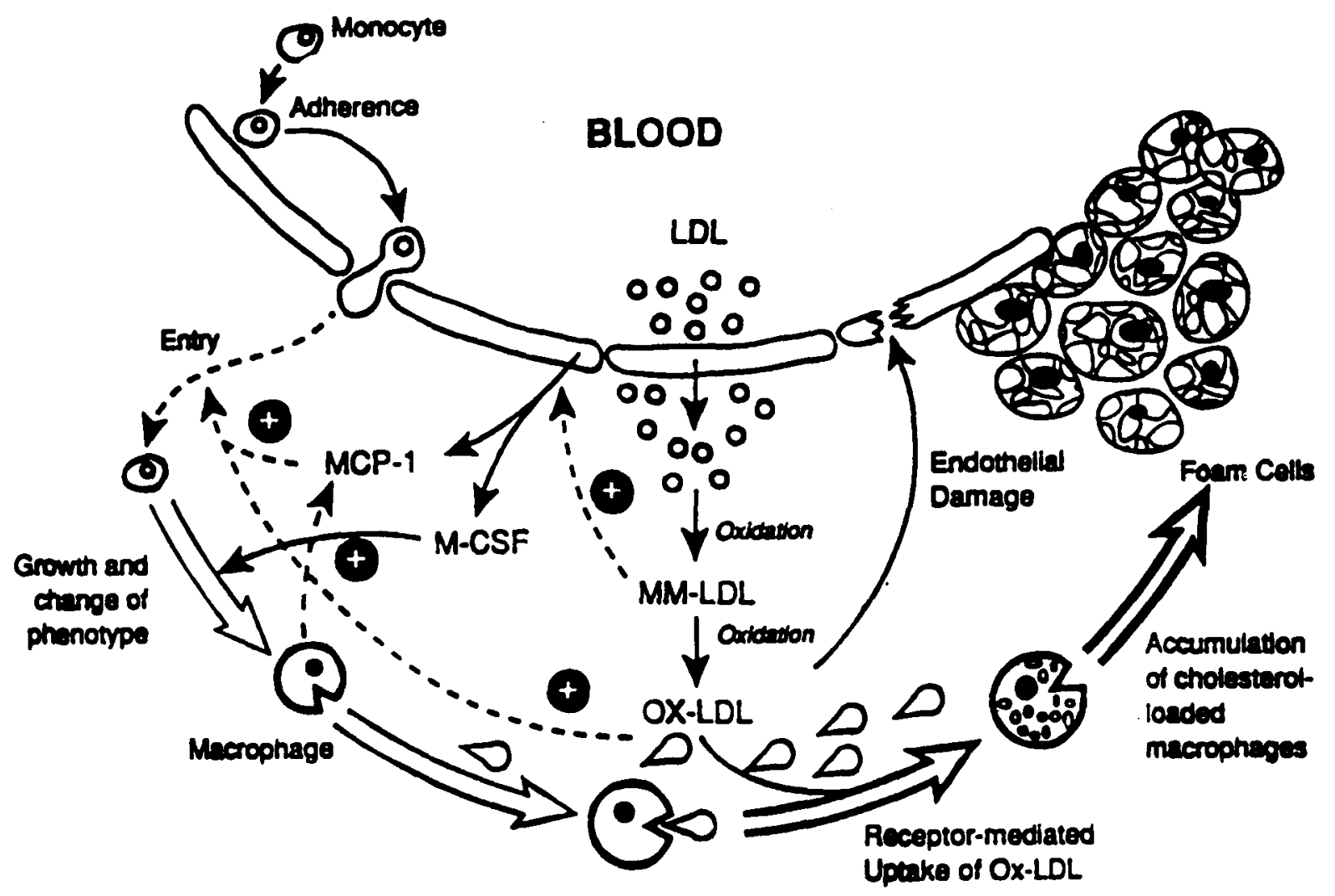

ARTEAY WALL

Figure 1. A schematic outline of the oxidative modification hypothesis, showing the several ways in which oxidized lowdensity lipoprotein (LDL) is potentially more atherogenic than native LDL. Monocytes, the major precursor for foam cells in the fatty streak, are shown adhering to the endothelium and then penetrating to the subendothelial space. Oxidized LDL can directly stimulate this by virtue of its lysolecithin content, and lightly oxidized LDL (MM-LDL) can stimulate indirectly by increasing the release of MCP-1 from endothelial cells. Oxidized LDL is a ligand for the scavenger receptor that is expressed as the monocyte differentiates to a tissue macrophage, and this leads to the accumulation of lipids in the developing foam cells. This monocyte/macrophage differentiation can be facilitated by the release of macrophage colony-stimulating factor (M-CSF) from endothelial cells under the influence of MM-LDL. Finally, oxidized LDL can induce endothelial damage and thus facilitate the atherogenic process by allowing entry of elements from the blood and by allowing adherence of platelets. Additional properties of oxidized LDL not shown here that may make it more atherogenic are the fact it is immunogenic and the fact that it interferes with response of arteries to endothelial-derived relaxation factor. Adapted from reference 14 with permission. 
insufficient to generate lipid-laden foam cells. ${ }^{18}$

In addition to the native LDL receptor, the macrophage expresses a second receptor known as the scavenger receptor. The scavenger receptor has a high affinity for modified forms of LDL such as acetylated and oxidized LDL, but not for native LDL. ${ }^{19}$ Uptake of the modified forms, primarily oxidized LDL, by the scavenger receptor is not limited by feedback inhibition. Thus, the inability of the scavenger receptor to down-regulate with the accumulation of cholesterol provides a mechanism for the continuous uptake of oxidized LDL and subsequent foam cell formation. This is believed to be the most significant route for the development of atherosclerotic lesions by oxidized LDL. ${ }^{20-24}$

Once the LDL has been oxidized it has several proatherogenic effects. For example, it directly stimulates the monocyte to penetrate into the subendothelial space of the arterial wall where it may undergo transformation into a macrophage (foam cell precursor) ${ }^{8}$ Oxidized LDL inhibits the migration of macrophages, causing them to be retained within the arterial wall. ${ }^{25}$ It also is cytotoxic to endothelial and smooth muscle cells. ${ }^{24}$ Mildly oxidized LDL may indirectly attract monocytes into the arterial wall by stimulating the release of monocyte chemoattractant protein-1 (MCP-1) from endothelial cells. ${ }^{26,}{ }^{27}$ In addition, the macrophage colony-stimulating factor (M-CSF) from endothelial cells facilitates the differentiation of monocytes to the tissue macrophage. ${ }^{26}$ Another potential atherogenic property of oxidized LDL is its ability to alter the response to endothelium-derived relaxing factor (EDRF), thus potentially inhibiting arterial relaxation. ${ }^{28}$

Evidence linking oxidative modification of LDL with the development of cholesterol-laden foam cells and the subsequent formation of the fatty streak prompted clinicians to study the effects of various antioxidants on atheroma formation. The earliest studies, done in animals, were conducted with probucol, a lipid-lowering agent with antioxidant properties. These studies indicated that probucol slowed the progression of atherosclerosis by a mechanism independent of its hypocholesterolemic effects. ${ }^{29-32}$ The drug may also result in many unwanted adverse effects, such as a reduction in the level of highdensity lipoprotein. ${ }^{33,34}$ Thus, a lot of attention has been focused on treatment with natural antioxidants.
Enhancing the endogenous antioxidant defense systems within the LDL particle decreases oxidation of LDL and slows the atherogenic process without producing undesirable effects. ${ }^{35}$ The endogenous defense system may be enhanced by micronutrient supplementation with lipophilic antioxidants such as $\alpha$-tocopherol and $\beta$-carotene, or by supplementing the aqueous phase antioxidant capacity with ascorbic acid..$^{35}$ Many of the data supporting such supplementation were derived from prospective cohort studies that evaluated the effects of dietary intake and plasma concentrations of vitamin $\mathrm{E}$, vitamin $C, \beta$-carotene, and selenium on the occurrence of CAD.

\section{Vitamin E}

Each LDL particle contains within it various lipophilic antioxidants, including $\alpha$-tocopherol, $\beta$-carotene, $\alpha$-carotene, lycopene, ubiquinol-10, $\gamma$-tocopherol, cryptoxanthin, cantaxanthin, and phytofluene. $^{36}$ They all prevent oxidation of the polyunsaturated fatty acids (PUFAs) bound to LDL, including linoleic acid, arachidonic acid, and docosahexanoic acid. The largest and most prominent of the antioxidants is $\alpha$-tocopherol, the main component of vitamin E. Each LDL particle contains approximately 6 molecules of $\alpha$ tocopherol; the remaining antioxidants in LDL account for $1 / 20$ th to $1 / 300$ th of that amount. ${ }^{36}$

Vitamin E plays a pivotal role in protecting LDL from lipid peroxidation. For example, heavy oxidative modification of LDL will not occur unless endogenous vitamin $E$ is depleted. ${ }^{23}$, 37, 38 Vitamin E competes for peroxyl radicals at a faster rate than PUFAs. Therefore, even minute amounts of vitamin $E$ can effectively protect a large number of PUFAs from oxidation. ${ }^{39}$ Since the correlation between oxidation and vitamin $\mathrm{E}$ is concentration dependent, the delay in oxidation of LDL can be increased by raising the plasma concentration of vitamin $E$ with dietary supplementation. ${ }^{40,41}$

\section{Epidemiologic Studies}

\section{Plasma Concentrations}

Cross-cultural epidemiologic studies conducted in Europe showed a strong inverse correlation between plasma vitamin $\mathrm{E}$ concentration and CAD. $^{42,43}$ During the World Health Organization/ Multinational Monitoring of Trends and Determinants in Cardiovascular Disease (WHO/MONICA) project, cardiovascular risk 
assessments and blood samples were taken on groups of approximately 100 healthy men age 40-49 years, from regions with different rates of CAD mortality. Plasma levels of essential antioxidants (vitamin $\mathrm{E}, \beta$-carotene, vitamin $C$, selenium) were inversely correlated with crosscultural CAD mortality in 16 European populations. The results of this study revealed only a weak direct correlation between the incidence of CAD and the two classic risk factors, total plasma cholesterol $\left(r^{2}=0.29, p=0.03\right)$ and blood pressure (diastolic $\mathrm{r}^{2}=0.25, \mathrm{p}=0.05$; systolic $\mathrm{r}^{2}=0.19, \mathrm{p}=0.09$ ). In addition, 12 of the 16 study populations had what was considered to be normal total plasma cholesterol levels of 5.7 to $6.2 \mathrm{mmol} / \mathrm{L}(220-240 \mathrm{mg} / \mathrm{dl})$. In this subgroup, total plasma cholesterol $\left(r^{2}=0.04, p=0.53\right)$ and blood pressure (diastolic $\mathrm{r}^{2}=0.08, \mathrm{p}=0.36$; systolic $\mathrm{r}^{2}=0.01, \mathrm{p}=0.80$ ) did not have a significant correlation with CAD mortality.

Among all populations evaluated, however, vitamins $E$ and $A$ had an inverse correlation with CAD mortality, strongest with vitamin $E$. The correlation coefficient was significant for lipidstandardized levels and absolute levels in the subgroup of populations with normal cholesterol $\left(\mathrm{r}^{2}=0.73, \mathrm{p}=0.0004\right.$ and $\mathrm{r}^{2}=0.63, \mathrm{p}=0.002$, respectively). The correlation coefficient was also highly significant for lipid-standardized vitamin E levels for all populations $\left(r^{2}=0.62\right.$, $\mathrm{p}=0.0003$ ). Thus, as found in this study, the risk of CAD mortality may relate more significantly to low vitamin $E$ levels than to traditional risk factors such as high total cholesterol levels and high blood pressure.

\section{Dietary Intake}

The Scottish Heart Health Study was conducted to determine the relationship between diet and the risk of CAD in a cross section of 10,359 men and women age 40-59 years, selected from patients of general practitioners throughout Scotland. ${ }^{44,45}$ The subjects completed questionnaires to provide information on food intake, sociodemographics, and health knowledge, as well as a separate one on chest pain. Based on this information, they were divided into three categories: the control group ( $73.3 \%, 3828$ men and 3790 women), a group with diagnosed CAD $(6 \%, 385$ men and 240 women), and one with undiagnosed CAD $(14.5 \%, 684$ men and 813 women). A total of 619 subjects were excluded before classification. The authors reported a significant reduction in the risk of having undiagnosed CAD among men in the highest quintile of dietary vitamin $\mathrm{E}$ intake $(p<0.05)$. However, this trend was not evident among women with diagnosed and undiagnosed CAD in the highest quintile of vitamin $E$ intake compared with those in the lowest quintile.

The correlation between vitamin $\mathrm{E}$ intake and the incidence of heart disease was investigated in the Nurses' Health Study. ${ }^{46}$ Detailed questionnaires were completed by 87,245 registered nurses, all women, regarding their dietary intake, lifestyle, and medical history. Subsequent questionnaires were sent every 2 years for follow-up on newly diagnosed illnesses, information on dietary and supplemental vitamin $E$ intake, and multivitamin supplementation. The follow-up was carried out over 8 years and was $97 \%$ complete.

An inverse correlation was observed between vitamin $E$ intake and CAD. After adjusting for other nutrients and coronary risk factors, the relative risk for major coronary disease (defined as nonfatal myocardial infarction or death due to coronary disease) among women in the highest quintile of total vitamin $E$ intake, including supplements, compared with women in the lowest was $0.66(p<0.001)$, which corresponds to a $34 \%$ reduction in risk for major coronary events. No apparent association was seen between dietary intake of vitamin $E$ without supplements and the relative risk for major coronary disease as defined above (relative risk $0.95, \mathrm{p}=0.99$ ).

The reduction in the risk of coronary disease was attributable to the intake of vitamin $E$ from supplements rather than from the diet. Doses less than $100 \mathrm{IU} /$ day were not of significant benefit in reducing the risk (relative risk 0.93), and no dose-response association was apparent when the dose was increased above $100 \mathrm{lU} /$ day. The relative risk was 0.56 for doses of 100-250 IU/day, 0.56 for 300-500 IU/day, and 0.58 for greater than $600 \mathrm{IU} / \mathrm{day}$. Overall, a $40 \%$ reduction in the risk of coronary disease was observed among middle-aged women who took vitamin E supplements compared with women who did not take supplements.

Similar results were observed in the Health Professionals Follow-up Study, a large, prospective study of 39,910 men health professionals between the ages of 40 and 75 years. ${ }^{47}$ All subjects completed a detailed questionnaire to assess diet and medical history. Follow-up questionnaires were sent biannually during the 4-year study. As in the Nurses' Health 
Study, an inverse correlation between vitamin E intake and relative risk of coronary disease was observed. The men in the highest quintile of vitamin $E$ intake had a $41 \%$ reduction in the ageadjusted relative risk of coronary disease (relative risk $0.59, \mathrm{p}=0.001$ ) compared with those in the lowest quintile of intake. The greatest reduction was in men taking daily doses of 100-249 IU. The relative risk did not decrease further when higher doses were taken. Duration of vitamin E use and risk of coronary disease were also inversely related.

Compared with nonusers of vitamin $\mathrm{E}$, men who claimed to have taken vitamin $E$ supplements for 10 or more years had an unadjusted relative risk of 0.65 . Those who reported taking multivitamins for 10 or more years had an unadjusted relative risk of 0.75 compared with nonusers. Thus, vitamin E supplements were of greater benefit in reducing the risk of coronary disease than multivitamins. Finally, an assessment of overall mortality revealed a $22 \%$ decrease in risk among men in the highest quintile of vitamin E intake, compared with those in the lowest quintile (relative risk $0.78, p=0.06$ ). Similar to the findings with nurses, vitamin E supplements were strongly associated with a significant reduction in the risk of coronary heart disease. The same association was not observed among individuals receiving vitamin E solely through dietary intake or multivitamins.

Not all trials evaluating the effects of vitamin E on CAD risk reported positive results. In fact, some prospective cohort studies failed to demonstrate an inverse correlation between the two. ${ }^{48-51}$ Three hundred ninety-five healthy men between ages 40 and 49 years were randomly selected from four regions in Europe (north Karelia, southwest Finland, Scotland, southern Italy) with different rates of CAD mortality. ${ }^{50,51}$ Of these four regions, north Karelia had the highest rate for these men, followed by southwest Finland, Scotland, and Italy. Vitamin E plasma concentrations were low among Scottish men $(p<0.001)$ but did not differ significantly among men in the other three regions. Thus, the studies failed to show a relationship between low vitamin E concentrations and cross-cultural differences in mortality from CAD. In this trial, the blood samples were subjected to deep freeze $\left(-70^{\circ} \mathrm{C}\right)$ for prolonged periods of time, which may have resulted in a substantial loss of vitamin E. Since the vitamin's stability under such conditions is unknown, the results from these studies may be flawed.

In summary, most cross-cultural European cohorts indicate that vitamin E plasma concentrations are inversely correlated with CAD mortality. There is also convincing evidence that vitamin E supplements are associated with a significant decrease in the risk and possibly the incidence of CAD due to the vitamin's antioxidant effects.

\section{Potential Adverse Effects}

Symptoms of vitamin E toxicity (hypervitaminosis E) are fatigue, weakness, nausea, headache, blurred vision, flatulence, and diarrhea. ${ }^{52}$ They are generally transient and mild. In large studies, including well-controlled double-blind trials of oral vitamin $E$ supplementation, doses as high as $3200 \mathrm{IU} /$ day rarely induced adverse events. ${ }^{53}$ As oral intake exceeds $100 \mathrm{IU} / \mathrm{day}$, the rate of tissue accumulation decreases. ${ }^{54}$ Only $0.6 \%$ of patients who received doses of 200-1000 IU/day for up to 11 years experienced adverse effects, including gastrointestinal symptoms, dermatitis, and fatigue. ${ }^{39}$ However, if the vitamin and oral anticoagulants are administered concomitantly, the risk of bleeding may be increased. ${ }^{52}$

In patients with vitamin $\mathrm{K}$ deficiency secondary to malabsorption, high-dose vitamin $E$ supplementation may exacerbate existing coagulation abnormalities. In patients without vitamin $\mathrm{K}$ deficiency, vitamin $\mathrm{E}$ has not been associated with coagulation abnormalities. ${ }^{55}$

Vitamin $E$ has a safety factor well over 100 times the recommended daily allowance. ${ }^{56}$ Nevertheless, it can potentially accumulate in adipose tissue, so long-term self-treatment with large doses is not devoid of risk.

A recent primary prevention trial, the AlphaTocopherol, Beta-Carotene (ATBC) Cancer Prevention Study, was conducted in 29,133 men smokers to determine whether supplementation with $\beta$-carotene $20 \mathrm{mg} /$ day, vitamin E $50 \mathrm{mg} /$ day, or both would reduce the incidence of lung cancer over a 5- to 8-year follow-up. ${ }^{57}$ Unfortunately, this study failed to show a beneficial effect of either agent. The change in the incidence of lung cancer among men who did as opposed to those who did not receive vitamin E was $-2 \%$ (95\% confidence interval $-14-12 \%$ ). This trial also unexpectedly revealed that among men who received $\alpha$-tocopherol compared with those who did not, more deaths were caused by hemorrhagic stroke ( $7.8 \%$ and $5.2 \%$, respectively) 
or cancers other than lung cancer $(34.7 \%$ and $30.4 \%$, respectively). However, there were fewer reported deaths due to ischemic heart disease and ischemic stroke among men receiving $\alpha$ tocopherol than in those who did not receive the agent. Overall mortality was $2 \%$ greater in groups receiving $\alpha$-tocopherol than in those not receiving $\alpha$-tocopherol ( $95 \% \mathrm{CI}-5-9 \%, \mathrm{p}=0.6$ ).

\section{$\beta$-Carotene}

In vitro studies have shown that vitamin $E$ is the first of the antioxidants in LDL to be consumed. Once the stores of vitamin $E$ are depleted, consumption of the carotenoids ( $\beta$ carotene, lycopene) ensues. Peroxidation of LDL does not occur until all of the carotenoids have been consumed. Thus, $\beta$-carotene and lycopene serve as a second line of defense against the oxidative modification of LDL. ${ }^{38,40,58}$

$\beta$-Carotene is thought to inhibit lipid peroxidation by trapping or deactivating singlet oxygen and free radicals. ${ }^{59}$ Experimental data indicate that its antioxidation activity may also play an important role in preventing atherosclerosis. $\beta$-Carotene effectively inhibits coppercatalyzed oxidation of LDL. ${ }^{60}$ The in vitro antioxidant effect appears to correlate with the plasma concentration of $\beta$-carotene, since LDL containing the higher $\beta$-carotene level displayed a substantially greater resistance to oxidative modification. In addition, $\beta$-carotene successfully inhibits macrophage modification of LDL and the subsequent uptake and degradation of oxidized LDL by the macrophage scavenger receptor. ${ }^{41}$ Thus, in vitro evidence strongly suggests that it has prominent antiatherogenic effects.

Epidemiologic Studies

\section{Plasma Concentrations}

Of the 16 European populations evaluated during the WHO/MONICA project, 12 had normal cholesterol (220-240 mg/dl) and blood pressure. Statistical analysis of those 12 populations revealed a weak inverse correlation between $\beta$-carotene plasma concentration and ischemic heart disease mortality $\left(r^{2}=0.21\right.$, $\mathrm{p}=0.14) .^{42,43}$

\section{Dietary Intake}

Several prospective cohort studies were conducted to determine if an inverse correlation exists between $\beta$-carotene intake and the risk of heart disease. The first and largest of these was the Nurses' Health Study. After adjustment for a variety of other coronary risk factors, the relative risk for $\mathrm{CAD}$ for women in the highest quintile of $\beta$-carotene intake compared with those in the lowest was 0.78 (95\% CI 0.59-1.03), which corresponds to a $22 \%$ reduction in risk of CAD. ${ }^{46,61}$

A significant trend toward a reduction in the risk of CAD with increased $\beta$-carotene intake was also observed in the Health Professionals Followup Study. ${ }^{47}$ The relative risk of CAD was $29 \%$ less among men with the highest $20 \%$ intake of $\beta$-carotene after adjusting for age and multivariate coronary risk factors (relative risk $0.71, \mathrm{p}=0.02$ ).

In the Scottish Heart Health Study the risk of having undiagnosed CAD was significantly lower in men within the highest quintile of $\beta$-carotene intake compared with those in the lowest. However, this trend was not observed among women. ${ }^{44,45}$

The association between dietary intake of $\beta$ carotene and the risk of cardiovascular disease (CVD) was recently investigated in a prospective cohort of 1299 elderly Massachusetts residents. ${ }^{62}$ Baseline dietary information was gathered with a food frequency questionnaire during a face-toface interview and was used to determine a $\beta$ carotene vegetable score for each subject, which corresponded with the number of servings of foods rich in $\beta$-carotene consumed per day. Follow-up information was collected by annual questionnaires mailed to each participant and an additional face-to-face interview. Over 4.75 years of follow-up, 161 deaths were due to CVD, of which 48 were attributed to myocardial infarction.

After adjusting for age and sex, the relative risk for CVD death among those in the highest $20 \%$ of $\beta$-carotene vegetable score was 0.54 , compared with those in the lowest $(p=0.004)$. For fatal myocardial infarction the relative risk was 0.25 $(\mathrm{p}=0.0019)$ after adjusting for age and sex. Thus the trend toward decreased cardiovascular mortality with increased dietary $\beta$-carotene intake was statistically significant in this cohort.

\section{Clinical Trials}

The Physicians' Health Study, a randomized, placebo-controlled, intervention trial was initiated in 1982 to examine the effects of lowdose aspirin on mortality from CVD and to determine if $\beta$-carotene reduces the incidence of cancer. $^{58,63}$ The trial was a two-by-two factorial design involving over 22,000 men physicians in 
the United States between ages 40 and 84 years. The subjects were randomized to one of four treatment groups: aspirin $325 \mathrm{mg}$ and placebo on alternate days; aspirin $325 \mathrm{mg}$ and $\beta$-carotene $50 \mathrm{mg}$ on alternate days; $\beta$-carotene $50 \mathrm{mg}$ and placebo on alternate days; and only placebo on all days.

Before randomization, a subgroup of 333 subjects was found to have a history of angina pectoris or coronary revascularization. Analysis of these subjects revealed that after adjusting for age and aspirin assignment, men receiving $\beta$ carotene $50 \mathrm{mg}$ on alternate days had a $44 \%$ reduction in all major cardiovascular events, including myocardial infarction, revascularization, and cardiac death, in comparison with placebo treatment (relative risk $0.56, p=0.046$ ). In addition, a significant reduction in all major vascular events of up to $49 \%$ was seen among those receiving $\beta$-carotene $50 \mathrm{mg}$ on alternate days (adjusted relative risk 0.51, p=0.015). Controlling for other coronary risk factors did not significantly alter these results. Thus, the preliminary results from this study strongly suggest that $\beta$-carotene may play an important role in the primary prevention of cardiovascular disease.

In summary, the results of these cohort trials provide convincing data supporting the theory that $\beta$-carotene may be beneficial in reducing the risk for and mortality from CAD.

\section{Potential Adverse Effects}

As the oral intake of $\beta$-carotene increases, a decline in intestinal absorption occurs, which ultimately reduces any risk for toxicity. Although $\beta$-carotene is a provitamin of vitamin $A$, the risk for vitamin A toxicity due to high intake of $\beta$ carotene is virtually nonexistent because as intake increases, conversion to vitamin A decreases. ${ }^{64}$ However, oral intake of $\beta$-carotene resulting in serum levels in excess of $0.4 \mathrm{mg} / \mathrm{dl}$ has been associated with carotenodermia, a reversible and benign yellowing of the skin. ${ }^{65}$ Excessive doses have also been associated with occasional loose stools. Ecchymoses and arthralgias are reported rarely. ${ }^{66}$ The safety of $\beta$ carotene has been established in doses of 15-50 $\mathrm{mg} / \mathrm{day}{ }^{67}$ The agent should be administered with caution to individuals with hepatic or renal dysfunction, since safety in this patient population has not been established. ${ }^{65}$

Men receiving $\beta$-carotene supplementation had an increased incidence of lung cancer over those who did not receive supplementation (change in incidence $18 \%, 95 \% \mathrm{Cl} 3-36 \%){ }^{57}$ Mortality rates between the groups were greatest for lung cancer (35.6\% and $30.8 \%$, respectively), ischemic heart disease $(77.1 \%$ and $68.9 \%)$, hemorrhagic stroke $(7.0 \%$ and $6.0 \%)$, and ischemic stroke $(8 \%$ and $6.5 \%)$. Overall mortality was $8 \%$ higher among recipients of $\beta$-carotene than nonrecipients $(95 \%$ CI $1-16 \%, p=0.02$ ).

\section{Vitamin C}

Vitamin $C$ is a water-soluble antioxidant that acts as the body's primary defense against peroxyl radicals formed in the aqueous phase. It is the only endogenous antioxidant in plasma capable of completely inhibiting oxidative modification of LDL by aqueous peroxyl radicals. ${ }^{68,69}$

When oxygen free radicals were produced in the aqueous phase, vitamin $C$ was rapidly consumed, resulting in a delay of the induction phase of the free radical chain mechanism. ${ }^{70}$ Vitamin $C$ was the first antioxidant to disappear, followed by slower elimination of vitamin $\mathrm{E}$. The level of vitamin $E$ did not decline until vitamin $C$ was completely eliminated.

Vitamin $C$ suppresses LDL peroxidation by intercepting the aqueous radicals, producing a break in the chain propagation of the free radical chain mechanism. In in vitro studies it failed to suppress the oxidation of LDL when it was added after the stores of vitamin $E$ had been exhausted, indicating that it is an effective and efficient weapon against aqueous radicals, with virtually no antioxidant activity against lipophilic peroxyl radicals. ${ }^{71}$

Although the other aqueous antioxidants (bilirubin, urate, sulfhydryl groups) can scavenge only some of the free radicals, ascorbate effectively sequesters all the aqueous peroxyl radicals before they diffuse into the lipid phase. Once all the vitamin $C$ has been consumed, any radicals that pass into the lipid phase are scavenged by the primary lipophilic antioxidant vitamin E. ${ }^{69}$ The protective effect of vitamin $C$ on vitamin $E$ also is well documented. Vitamin $C$ acts to regenerate vitamin $E$ at the water-lipid interphase by reducing the tocopheroxyl radical back to the active tocopherol form. ${ }^{72,73}$

Epidemiologic Studies

\section{Plasma Concentration}

When the 12 European populations with normal cholesterol and blood pressure of the 
WHO/MONICA project were examined, plasma vitamin $C$ concentration showed a significant inverse correlation with the incidence of CAD $\left(r^{2}=0.41, p=0.03\right),{ }^{43}$ However, when all 16 populations were considered, the relationship was no longer significant $\left(r^{2}=0.11, p=0.22\right)$.

\section{Dietary Intake}

The relationship between ascorbate intake and mortality was evaluated in 14,407 subjects between 25 and 74 years of age in a prospective cohort study, the First National Health and Nutrition Examination Study (NHANES). ${ }^{74}$ Extensive diet and nutrition information, including vitamin supplementation use, was gathered between 1971 and 1974 by personal interviews, questionnaires, and food frequency surveys. A follow-up survey was subsequently conducted in 1982-1984 in which information was collected from $90 \%$ of the original participants. The final results are based on a population of 10,550 subjects. They were divided into three categories based on daily vitamin $C$ intake (vitamin $C$ index): $0-49 \mathrm{mg}$, $50+\mathrm{mg}$ without regular supplements, and $50+$ mg with regular supplements. The standardized mortality ratio (SMR) was then determined for the subgroups that were defined by several variables, including age, sex, and vitamin $C$ index. The SMR for each subgroup was calculated as the number of observed deaths divided by the number of expected deaths, expressed as a percentage. Thus, comparisons were made relative to all United States Caucasians for whom the SMR is defined to be 1.00. The results showed that among those with the highest vitamin $C$ intake $(50+\mathrm{mg}$ and regular supplements), the SMR for all CVD, defined as codes 390 through 459 by the ninth revision of the International Classification of Diseases (ICD 9 ), was $0.58(0.41-0.78)$ for men and 0.75 (0.55-0.99) for women. An inverse correlation between SMR and vitamin $C$ intake was strong for all CVD for men and weak for women.

Results from the Scottish Heart Health Study revealed that, compared with men in the lowest quintile of vitamin $C$ intake, men in the highest quintile were at a significantly lower risk for having undiagnosed CAD ( $\mathrm{p}=0.05) .44,45$ This dose-response relationship did not hold true for women.

Data in the Nurses' Health Study strongly suggested that increased intake of vitamin $C$ may be associated with a decreased risk of CAD. ${ }^{46,75}$
Among women in the highest quintile of vitamin $C$ intake compared with those in the lowest, the relative risk was 0.65 (95\% CI $0.49-0.86$ ) after multivariate adjustment for other coronary risk factors. ${ }^{75}$

Some cohort studies reported that an inverse association between vitamin $C$ intake and the incidence of heart disease does not exist. For instance, in the Health Professionals Follow-up Study, among subjects in the highest quintile of vitamin $C$ intake (median $1162 \mathrm{mg} /$ day) compared with those in the lowest (median 92 $\mathrm{mg} /$ day), the multivariate relative risk was 1.25 (95\% CI 0.91-1.71). ${ }^{47}$ A cross-sectional trial also failed to detect a specific relationship between plasma vitamin $C$ concentrations and CAD. ${ }^{51}$

In conclusion, vitamin $C$ has a weak inverse correlation with the incidence and mortality of $C A D$, and this may not be an independent relationship. Vitamin $C$ may not be as promising in preventing $C A D$ as vitamin $E$ and $\beta$-carotene.

\section{Potential Adverse Effects}

Vitamin $C$ is primarily eliminated by the kidneys, and evidence indicates that the renal threshold is attained at a plasma concentration of $0.8-1.4 \mathrm{mg} / \mathrm{dl}$. The vitamin appears in urine as the plasma concentration exceeds the renal threshold. ${ }^{76-78}$ In addition, as the dose is increased, absorption decreases. This doseabsorption relationship was substantiated in several clinical trials. At a dose of $30 \mathrm{mg}, 95 \%$ of the drug is absorbed, however, with doses of $6 \mathrm{~g}$ and $12 \mathrm{~g}$ absorption decreases to $25 \%$ and $16 \%$, respectively. ${ }^{79,80}$

Similar to the other antioxidants, the potential for a vitamin $C$ overdose or toxicity is highly unlikely. However, large doses of 1-5 g/day may cause diarrhea, nausea, and vomiting. ${ }^{77}$ Large doses may also result in precipitation of oxalate, cysteine, or urate renal stones if the urine becomes acidic during therapy. ${ }^{81}$ Oxalate also accumulates in patients with chronic renal failure and those receiving long-term hemodialysis, ${ }^{82}$ and these individuals should be cautioned against taking large doses of vitamin $C$. The vitamin is contraindicated in patients with hemochromatosis and other conditions characterized by iron overload. ${ }^{83}$ Maternal ingestion of doses in excess of $400 \mathrm{mg} /$ day during pregnancy was associated with scorbutic conditions in infants. ${ }^{84}$ Vitamin $C$ dependency was documented in adults consuming large quantities of ascorbate. ${ }^{85}$ 


\section{Selenium}

Selenium is an essential trace element in humans. It is a necessary constituent of the selenoenzyme glutathione peroxydase (GSH-Px), an enzyme thought to act in the destruction of hydrogen peroxide and organic hydroperoxides ${ }^{86,87}$ Selenium may be a vital component in protecting the coronary endothelium from oxidative damage. The dependence of GSH-Px activity on selenium prompted many investigators to study the possibility of an inverse relationship between cardiovascular disease and selenium concentration.

An inverse correlation was seen between plasma selenium concentrations and the severity of coronary atherosclerosis as determined by arteriography. ${ }^{88}$ The absence of narrowing as great as $50 \%$ of any coronary arterial lumen was defined as "zero-vessel" disease. One-, two-, and three-vessel diseases were defined as a narrowing of $50 \%$ or more in the corresponding number of the three major coronary arteries or their branches. Of the 106 patients in this study, 15 had zero-vessel disease (control group), 24 onevessel, 19 two-vessel, and 33 three-vessel disease. The mean plasma selenium concentrations of the patients with two- $(111.3 \mu \mathrm{g} / \mathrm{L})$ and three-vessel disease $(105.2 \mu \mathrm{g} / \mathrm{L})$ were significantly less than that of the control group $(136.3 \mu \mathrm{g} / \mathrm{L}, \mathrm{p} \leq 0.05)$. Selenium concentrations of patients with onevessel disease $(119.2 \mu \mathrm{g} / \mathrm{L})$ did not differ significantly from those in the control group. Thus, the total selenium concentration appeared to be inversely related to the severity of coronary atherosclerosis. The question remains as to whether a decrease in serum selenium concentration contributes to the development of atherosclerosis, is a result of atherosclerosis, or is simply a side effect of atherogenesis with no direct relevance to it.

A prospective epidemiologic study conducted in Finland revealed a link between serum selenium concentrations below $45 \mu \mathrm{g} / \mathrm{L}$ and an increased risk of $\mathrm{CHD}$, cardiovascular disease, and myocardial infarction. ${ }^{89}$ In addition, the serum level was inversely associated with platelet aggregability and positively associated with plasma high-density lipoprotein cholesterol. ${ }^{90} \mathrm{~A}$ significantly lower activity of GSH-Px in platelets was observed in patients who suffered an acute myocardial infarction. ${ }^{91}$ A similar association was seen between serum selenium and the incidence of CHD and acute myocardial infarction. ${ }^{92}$ The concentrations were significantly lower in patients with acute infarction and those with CAD $(\mathrm{p}<0.01)$. However, much of the information on selenium is controversial, and several studies failed to find a consistent association between serum selenium and the risk of CAD. ${ }^{43,48,49,93}$

Based on epidemiologic findings, selenium may be of potential benefit in preventing $C A D$, but the data are inconsistent. Until it is studied in more detail, the true effects of selenium on heart disease will remain unknown.

\section{Potential Adverse Effects}

Toxicity is highly unlikely when selenium is taken at the recommended dosages, although excessive amounts can be lethal. ${ }^{94}$ Symptoms of selenium toxicosis include hair loss, weak nails, dermatitis, dental defects, gastrointestinal disorders, nervousness, mental depression, metallic taste, vomiting, and garlic odor of breath and sweat. Acute selenium poisoning may result in death. The sequence of events preceding death usually consists of fulminant peripheral vascular collapse, internal vascular congestion, diffuse hemorrhea, pulmonary congestion and edema, and coma. ${ }^{94}$ Toxicity is usually confined to individuals living in seleniferous areas ${ }^{95}$ or those with long-term industrial exposure. ${ }^{96}$

The intake required to elicit toxicity is unknown. However, doses of 100-600 $\mu \mathrm{g} /$ day have been associated with toxicity. ${ }^{97}$ The maximum recommended dietary intake for adults is $200 \mu \mathrm{g} /$ day. ${ }^{98}$

\section{Recommendations and Conclusions}

Although it is speculative at this time, patients who may gain the most benefit from dietary supplements of antioxidants are those in highrisk groups, such as those with a history of angina pectoris, ${ }^{63}$ coronary revascularization, ${ }^{63}$ hyperlipidemia, ${ }^{42,}{ }^{43}$ hypertension, ${ }^{42,43}$ and myocardial infarction. ${ }^{91,92}$ Since smokers have decreased LDL ascorbate and $\beta$-carotene levels, and are especially prone to oxidative stress, they may also be good candidates for antioxidant therapy. ${ }^{99-101}$

Most of the data reported in the literature are supportive of supplemental vitamin $E$ to prevent $C A D$, but less supportive of $\beta$-carotene and vitamin $C$. Clearly, large-scale, placebocontrolled, comparative trials are warranted, ${ }^{102}$ but until they are performed, the optimum antioxidant and dosage cannot be established.

The literature regarding vitamin $\mathrm{E}$ indicates that the relative risk of developing coronary 
disease in middle-aged women was most significantly reduced in those who had a median intake of $208 \mathrm{IU} /$ day. ${ }^{46}$ Similarly, the greatest reduction in risk was observed in men taking $100-249 \mathrm{IU} / \mathrm{day}^{47}$ Doses greater than $400-800$ IU/day have not been associated with an increase in efficacy.

Since $\beta$-carotene is essentially nontoxic, it may be given in "maximum non-yellowing doses." 102 Serum levels of $\beta$-carotene greater than $0.4 \mathrm{mg} / \mathrm{dl}$ were associated with a benign yellowing of the skin. ${ }^{65}$ Doses of $15-50 \mathrm{mg} /$ day are established to be safe. ${ }^{67}$

In prospective cohort studies, doses of vitamin $C$ above $50 \mathrm{mg} /$ day were associated with a reduced risk of coronary heart disease. ${ }^{45}$ Doses greater than $1 \mathrm{~g}$ /day do not significantly alter plasma concentrations of vitamin $\mathrm{C}^{103}$

The recommended daily allowance for selenium is $70 \mu \mathrm{g} / \mathrm{day}$ for adult men and 55 $\mu \mathrm{g} /$ day for adult women. These amounts will allow maximization of GSH-Px. ${ }^{104}$ The maximum recommended dietary intake of selenium is $200 \mu \mathrm{g} /$ day. ${ }^{98}$ The average American adult consumes approximately 83-129 $\mu \mathrm{g} /$ day, and consequently, normal blood concentrations range from $58-234 \mu \mathrm{g} / \mathrm{L}(0.74-2.97 \mathrm{mmol} / \mathrm{L})$ and normal serum levels range from $46-143 \mu \mathrm{g} / \mathrm{L}$ $(0.58-1.82 \mathrm{mmol} / \mathrm{L}){ }^{105}$ In an epidemiologic study, a significant decrease in coronary atherosclerosis was observed in subjects with plasma concentrations of $136.3 \mu \mathrm{g} / \mathrm{L}$, compared with patients with total plasma selenium of 105.2 $\mu \mathrm{g} / \mathrm{L}(\mathrm{p} \leq 0.01){ }^{88}$ Patients in this study were not given supplemental selenium before the plasma was sampled.

The recommendation of specific dosages of antioxidants to prevent atherosclerosis is premature since the issue remains controversial. Although most of the observational data strongly suggest a protective effect of antioxidant supplements on the incidence of CAD, they are inconclusive. In addition, long-term safety issues associated with supplemental doses of vitamin $\mathrm{E}$, $\beta$-carotene, and vitamin $C$ have not been resolved. It is important to note that sufficient amounts of $\beta$-carotene and vitamin $C$ can be achieved through dietary intake. Thus, a daily multivitamin supplement may be appropriate for some patients, but should not be routine for all, especially those who consume a balanced diet. In contrast, it appears unlikely that sufficient quantities of vitamin $\mathrm{E}$ can be obtained from foods or even standard multivitamins.

The Harvard Physicians' Health Study is the only large-scale intervention trial that has reported preliminary results. This trial is continuing, and final results of the $\beta$-carotene arm should be made available in the near future. Other prospective primary prevention trials also are in progress, but until the results are available it may be prudent to avoid providing general recommendations regarding the use of antioxidants for preventing cardiovascular disease.

\section{References}

1. Genton RE, Sobel BE. Acute myocardial infarction in perspective. In: Messerli $\mathrm{FH}$, ed. Cardiovascular drug therapy. Philadelphia: WB Saunders, 1990:2-8.

2. National Heart, Lung, and Blood Institute. Morbidity and mortality: chartbook on cardiovascular, lung, and blood diseases. Bethesda, MD: U.S. Department of Health and Human Services, Public Health Service, National Institutes of Health, 1992.

3. Graves EJ. 1983 summary: national hospital discharge survey. Rockville, MD: National Center for Health Statistics, 1984.

4. Hlatky MA, Cotugno HE, Mark DB, et al. Trends in physician management of uncomplicated acute myocardial infarction, 1970 to 1987. Am J Cardiol 1988;61:515-18.

5. Gonzalez ER, Sypniewski E. Acute myocardial infarction: diagnosis and treatment. In: DiPiro JT, Talbert RL, Hayes PE, et al, eds. Pharmacotherapy. New York: Elsevier, 1992:231-54.

6. Gotto AM, Phil D, Farmer JA. Risk factors for coronary artery disease. In: Braunwald E, ed. Heart disease: a textbook of cardiovascular medicine. Philadelphia: WB Saunders, 1988:1153-90.

7. Neufeld HN, Goldbourt U. Coronary heart disease: genetic aspects. Circulation 1983;67:943-7.

8. Steinberg D, Parthasarathy S, Carew TE, et al. Beyond cholesterol: modifications of low density lipoprotein that increase its atherogenicity. N Engl J Med 1989;320:915-24.

9. Goldstein JL, Ho YK, Basu SK, et al. Binding site on macrophages that mediates uptake and degradation of acetylated low density lipoprotein, producing massive cholesterol deposition. Proc Natl Acad Sci 1979;76:333-7.

10. Lyons TJ. Oxidized low density lipoproteins: a role in the pathogenesis of atherosclerosis in diabetes. Diabet Med 1991;8:411-19.

11. Witztum JL, Steinberg D. Role of oxidized low-density lipoprotein in atherogenesis. J Clin Invest 1991;88:1785-92.

12. Gerrity RG. The role of the monocyte in atherogenesis. I. Transition of blood-borne monocytes into foam cells in fatty lesions. N Engl J Med 1981;103:181-90.

13. Fogelman AM, Schechter I, Hokom $M$, et al Malondialdehyde alteration of low density lipoproteins leads to cholesteryl ester accumulation in human monocytemacrophages. Proc Natl Acad Sci 1980;77:2214-18.

14. Steinberg D. Antioxidants and atherosclerosis: a current assessment. Circulation 1991;84:1420-5.

15. Esterbauer $\mathbf{H}$, Rotheneder $\mathbf{M}$, Striegl G. Vitamin $E$ and other lipophilic antioxidants protect LDL against oxidation. Fat Sci Technol 1989;91:316-24.

16. Esterbauer H, Dieber-Rotheneder M, Striegl G, et al. Role of vitamin $E$ in preventing the oxidation of low-density lipoprotein. Am J Clin Nutr 1991;53:314S-21.

17. Stary HC. The evolution of human atherosclerotic lesions West Point, PA: Merck \& Co., 1993.

18. Brown MS, Goldstein JL. A receptor-mediated pathway for cholesterol homeostasis. Science 1986;232:34-47.

19. Brown MS, Goldstein JL. Lipoprotein metabolism in the macrophage: implications for cholesterol deposition in atherosclerosis. Annu Rev Biochem 1983;52:223-61. 
20. Henrickson T, Mahoney EM, Steinberg D. Enhanced macrophage degradation of low density lipoprotein previously incubated with cultured endothelial cells: recognition by the receptor for acetylated low density lipoproteins. Proc Natl Acad Sci U S A 1981;78:6499-503.

21. Henrickson T, Mahoney EM, Steinberg D. Interactions of plasma lipoproteins with endothelial cells. Ann NY Acad Sci 1982;401:102-16.

22. Henrickson T, Mahoney EM, Steinberg D. Enhanced macrophage degradation of biologically modified low density lipoprotein. Arteriosclerosis 1983;3:149-59.

23. Morel DW, DiCorleto PE, Chisolm GM. Endothelial and smooth muscle cells alter low density lipoprotein in vitro by free radical oxidation. Arteriosclerosis 1984:4:357-64.

24. Steinbrecher UP, Parthasarathy S, Leake DS, et al Modification of low density lipoprotein by endothelial cells involves lipid peroxidation and degradation of low density lipoprotein phospholipids. Proc Natl Acad Sci U S A 1984;83:3883-7.

25. Quinn MT, Parthasarathy S, Fong LG, et al. Endothelial cellderived chemotactic activity for mouse peritoneal macrophages and the effects of modified forms of low density lipoprotein. Proc Natl Acad Sci U S A 1985;82:5949-53.

26. Rajavashisth TB, Andalibi A, Territo MC, et al. Induction of endothelial cell expression of granulocyte and macrophage colony-stimulating factors by modified low-density lipoproteins. Nature 1990;344:254-7.

27. Yoshimura T, Robinson EA, Tanaka S, et al. Purification and amino acid analysis of two human monocyte chemoattractants produced by phytohemagglutinin-stimulated human peripheral blood mononuclear leukocytes. J Immunol 1989;142:1956-62.

28. Kugiyama K, Kerns SA, Morrisett JD, et al. Impairment of endothelium-dependent arterial relaxation by lysolecithin in modified low density lipoprotein. Nature 1990;344:160-2.

29. Kita T, Nagano $\mathbf{Y}$, Yokode $\mathbf{M}$, et al. Probucol prevents the progression of atherosclerosis in Watanabe heritable hyperlipidemic rabbit, an animal model for familial hypercholesterolemia. Proc Natl Acad Sci U S A 1987;84:5928-31.

30. Carew TE, Schwenke DC, Steinberg D. Antiatherogenic effect of probucol unrelated to its hypocholesterolemic effect: evidence that antioxidants in vivo can selectively inhibit low density lipoprotein degradation in macrophage-rich fatty streaks slowing the progression of atherosclerosis in the WHHL rabbit. Proc Natl Acad Sci U S A 1987;84:7725-9.

31. Steinberg D, Carew TE, Parthasarthy $S$. In vivo inhibition of foam cell development by probucol in Watanabe rabbits. Am J Cardiol 1988;62:6B-12.

32. Matsuzawa Y, Shizuya Y, Funahashi T, et al. Selective reduction of cholesterol in HDL2 fraction by probucol in familial hypercholesterolemia and hyperHDL2 cholesterolemia with abnormal cholesteryl ester transfer. Am J Cardiol 1988;62:66B-72

33. Goldberg RB. Probucol enhances cholesterol efflux from cultured human skin fibroblasts. Am J Cardiol 1988; $62: 57 \mathrm{~B}-9$

34. Sirtori CR. Changes in high-density lipoprotein subfraction distribution and increased cholesteryl ester transfer after probucol. Am J Cardiol 1988;62:73B-6

35. Jialal I, Fuller CJ. Oxidized LDL and antioxidants. Clin Cardiol 1993;16(suppl):I6-9.

36. Esterbauer $\mathbf{H}$, Puhl $\mathbf{H}$, Dieber-Rotheneder $\mathbf{M}$, et al. Effect of antioxidants on oxidative modification of LDL. Ann Intern Med 1991;23:573-81.

37. Esterbauer $H$, Jurgens $G$, Quehenberger $O$, et al. Autoxidation of human low density lipoprotein: loss of polyunsaturated fatty acids and vitamin $E$ and generation of aldehydes. J Lipid Res 1987;28:495-509.

38. Esterbauer $\mathbf{H}$, Striegl $\mathbf{G}$, Puhl $\mathbf{H}$, et al. The role of vitamin $\mathrm{E}$ and carotenoids in preventing oxidation of low density lipoproteins. Ann NY Acad Sci 1989;570:254-67.

39. Burton GW, Traber MG. Vitamin E: antioxidant activity, biokinetics, and bioavailability. Annu Rev Nutr 1990;10:357-82.

40. Esterbauer H, Striegl G, Puhl H, et al. Continuous monitoring of in vitro oxidation of human low density lipoprotein. Free Radic Res Comm 1989;6:67-75.

41. Jialal I, Grundy SM. In vivo alpha-tocopherol supplementation inhibits LDL oxidation. Circulation 1991;84:1178

42. Gey KF, Puska P. Plasma vitamins E and A inversely related to mortality from ischemic heart disease in cross-cultural epidemiology. Ann NY Acad Sci 1989;570:268-82.

43. Gey F, Puska P, Jordan P, et al. Inverse correlation between plasma vitamin $\mathrm{E}$ and mortality from ischemic heart disease in cross-cultural epidemiology. Am J Clin Nutr 1991; 53(suppl):326S-4.

44. Bolton-Smith C, Woodward M, Tunstall-Pedoe H. The Scottish heart health study: dietary intake by food frequency questionnaire and odds ratios for coronary heart disease risk. I. The macronutrients. Eur J Clin Nutr 1992;46:75-84.

45. Bolton-Smith $C$, Woodward $M$, Tunstall-Pedoe $H$. The Scottish heart health study: dietary intake by food frequency questionnaire and odds ratios for coronary heart disease risk. II. The antioxidant vitamins and fiber. Eur J Clin Nutr 1992;46:85-93.

46. Stampfer MJ, Hennekens C.H, Manson JE, et al. Vitamin E consumption and the risk of coronary disease in women. $\mathrm{N}$ Engl J Med 1993;328:1444-9.

47. Rimm EB, Stampfer MJ, Ascherio A, et al. Vitamin E consumption and the risk of coronary heart disease in men. $\mathrm{N}$ Engl J Med 1993;328:1450-6.

48. Kok FJ, de Bruijn AM, Vermeeren $R$, et al. Serum selenium vitamin anti-oxidants and cardiovascular mortality: a 9-year follow-up study in the Netherlands. Am J Clin Nutr 1987;45:462-8

49. Salonen JT, Salonen R, Penttilae $\mathbf{R}$, et al. Serum fatty acids, apolipoproteins, selenium and vitamin anti-oxidants and the risk of death from coronary artery disease. Am J Cardiol 1985;56:226-31.

50. Riemersma RA, Wood DA, Butler $S$, et al. Linoleic acid content in adipose tissue and coronary heart disease. Br Med J $1986 ; 292: 1423-7$.

51. Riemersma RA, Oliver M, Elton RA, et al. Plasma antioxidants and coronary heart disease: vitamins $C$ and $E$ and selenium. Eur J Clin Nutr 1990;44:143-50.

52. Anonymous. Vitamin E monograph. In: Olin BR, Hebel SK Dombek CE, et al, eds. Drug facts and comparisons. St. Louis: Facts and Comparisons, 1994:5-5a.

53. Bendich A, Machlin L. Safety of oral intake of vitamin E. Am J Clin Nutr 1988;48:612-19.

54. Sitren HS. Vitamin E. In: Baumgartner TG, ed. Clinical guide to parenteral micronutrition, 2nd ed. Fujisawa, Japan: U S A Inc., 1991:389-408.

55. Machlin LJ. Vitamin E. In: Machlin LJ, ed. Handbook of vitamins, 2nd ed. New York: Marcel Dekker, 1991:99-143.

56. Marks J. The safety of the vitamins: an overview. In: Walter P, Brubacher $G$, Stahelin $H$, eds. Elevated dosages of vitamins. Toronto: Hans Huber, 1989:12-20.

57. Heinonen OP, Huttunen JK, Albanes D. The effect of vitamin $E$ and beta carotene on the incidence of lung cancer and other cancers in male smokers. N Engl J Med 1994;330:1029-35.

58. Gerster $\mathbf{H}$. Potential role of $\beta$-carotene in the prevention of cardiovascular disease. Int J Vitam Nutr Res 1991;61:277-91.

59. Burton GW, Ingold KU. $\beta$-Carotene: an unusual type of lipid antioxidant. Science 1984;224:569-73.

60. Quintao E, Witztum JL, Parthasarathy S, et al. Role of $\beta$ carotene in the oxidative modification of low density lipoproteins [abstr]. Arteriosclerosis 1989;9:758a.

61. Manson JE, Stampfer MJ, Willet WC, et al. A prospective study of anti-oxidant vitamins and the incidence of coronary heart disease in women [abstr]. Circulation 1991;84:2168.

62. Gaziano JM, Manson JE, Branch LG, et al. Dietary betacarotene and decreased cardiovascular mortality in an elderly cohort [abstr]. J Am Coll Cardiol 1992;19:377A.

63. Gaziano JM, Manson JE, Redker PM, et al. Beta-carotene 


\section{NATURAL ANTIOXIDANTS TO PREVENT ATHEROSCLEROSIS Odeh and Cornish}

therapy for chronic stable angina [abstr]. Circulation 1992;82:202.

64. Goodwin TW. Mammals. In: Walworth T, ed. The biochemistry of the carotenoids. New York: Chapman \& Hall, 1984:173-95.

65. Micozzi MS, Brown ED, Taylor PR, et al. Carotenodermia in men with elevated carotenoid intake from foods and $\beta$ carotene supplements. Am J Clin Nutr 1988;48:1061-4.

66. Anonymous. Beta-carotene monograph. In: Olin BR, Hebel SK, Dombek CE, et al, eds. Drug facts and comparisons. St. Louis: Facts and Comparisons, 1994:744

67. Bendich A. The safety of $\beta$-carotene. Nutr Cancer 1988;11:207-14.

68. Frei B, Stocker R, Ames BN. Anti-oxidant defenses and lipid peroxidation in human blood plasma. Proc Natl Acad Sci U S A 1988;85:9748-52.

69. Frei B, Stocker R, England L, et al. Ascorbate: the most effective antioxidant in human blood plasma. In: Emerit $\mathbf{I}$, Packer L, eds. Antioxidants in therapy and preventive medicine. London: Plenum Press, 1990:155-63.

70. Niki E. Antioxidants in relation to lipid peroxidation. Chem Phys Lipids 1987;44:227-53.

71. Sato K, Niki E, Shimasaki H. Free radical-mediated chain oxidation of low density lipoprotein and its synergistic inhibition by vitamins $\mathrm{E}$ and $\mathrm{C}$. Arch Biochem Biophys 1990;279:402-5.

72. Niki E. Interaction of ascorbate and $\alpha$-tocopherol. Ann NY Acad Sci 1987;498:186-99.

73. Niki E, Yamamoto $Y$, Takahashi $M$, et al. Inhibition of oxidation of biomembranes by tocopherol. Ann NY Acad Sci 1989;570:23-31.

74. Enstrom JE, Kanim LE, Klein MA. Vitamin C intake and mortality among a sample of the United States population. Epidemiology 1992;3:194-202.

75. Manson JE, Meir J, Stampfer MJ, et al. A prospective study of vitamin $\mathrm{C}$ and incidence of coronary heart disease in women [abstr]. Circulation 1992;85:865.

76. Melethil S, Subrahmayam MB, Chang J, et al. Megadoses of vitamin C: a pharmacokinetic evaluation. Ann NY Acad Sci 1987;498:491-3.

77. Hodges RE. Vitamin C. In: Alfin-Slater RB, Kritchevsky P, eds Human nutrition: a comprehensive treatise. New York: Plenum Press, 1980:73-96.

78. Moser U, Bendich A. Vitamin C. In: Machlin L, ed. Handbook of vitamins. New York: Marcel Dekker, 1991:195-232.

79. Kallner A, Hartmann D, Hornig D. On the absorption of ascorbic acid in man. Int J Vitam Nutr Res 1977;47:383-8.

80. Kubler W, Gehler J. Kinetics of intestinal absorption of ascorbic acid: calculated non-dosage-dependent absorption processes. Int J Vitam Nutr Res 1970;40:442-53.

81. Anonymous. Vitamin C monograph. In: Olin BR, Hebel SK, Dombek CE, et al, eds. Drug facts and comparisons. St. Louis: Facts and Comparisons, 1994:10a-c.

82. Balcke P, Schmidt $\mathbf{P}$, Zaggornik J, et al. Ascorbic acid aggravates secondary hyperoxalemia in patients on chronic hemodialysis. Ann Intern Med 1984;101:344-5.

83. Rivers JM. Safety of high-level vitamin C ingestion. Ann NY Acad Sci 1987;498:225-54.

84. Cochrane W. Overnutrition in prenatal and neonatal life: a problem. Can Med Assoc J 1965;93:893-9.

85. Rhead WJ, Schranzer GN. Risk of long-term ascorbic acid overdosage. Nutr Rev 1971;29:262-3.

86. Rotruck JT, Pope AL, Ganther HE, et al. Selenium: biochemical role as a component of glutathione peroxidase. Science 1973;179:588.

87. Awasthi YC, Beutler CE, Srivastava SK. Purification and properties of human erythrocyte glutathione peroxidase. J Biol Chem 1975:250:5144.

88. Moore JA, Noiva R, Wells IC. Selenium concentrations in plasma of patients with arteriographically defined coronary atherosclerosis. Clin Chem 1984;30:1171-3.

89. Salonen JT, Alfthan G, Pikkarainen J, et al. Association between cardiovascular death and myocardial infarction and serum selenium in a matched-pair longitudinal study. Lancet 1982:2:175-9.

90. Salonen JT, Salonen R, Seppanen K, et al. Relationship of serum selenium and antioxidants to plasma lipoproteins, platelet aggregability and prevalent ischaemic heart disease in eastern Finnish men. Atherosclerosis 1988;70:155-60.

91. Wang YX, Bocker K, Reuter $\mathbf{H}$, et al. Selenium and myocardial infarction: glutathione peroxidase in platelets. Klin Wochenschr 1981;59:817-18.

92. Oster $O$, Drexler M, Schenk J, et al. The serum selenium concentration of patients with acute myocardial infarction. Ann Clin Res 1986;18:36-42.

93. Ringstad J, Thelle D. Risk of myocardial infarction in relation to serum concentrations of selenium. Acta Pharmacol Toxicol 1986;59:336-9.

94. American Regent Laboratories, Inc. Selenium solution package insert. Shirley, NY: 1986 September.

95. Rosenfield I, Beath DA. Selenium, geobotany, biochemistry, toxicity and nutrition. New York: Academic Press, 1964.

96. Diskin DJ, Tomasso CL, Alper JC, et al. Long-term selenium exposure. Arch Intern Med 1979;139:824-6.

97. Schrauzer GN, White DA. Selenium in human nutrition dietary intakes and effects of supplementation. Bioinorg Chem 1978;8:303-18.

98. Sakurai $\mathrm{H}$, Tsuchiya $\mathrm{K}$. A tentative recommendation for the maximum daily intake of selenium. Environ Physiol Biochem 1975;5:107-18

99. Chow CK, Thacker RR, Chanchit C, et al. Lower levels of vitamin $C$ and carotenes in plasma of cigarette smokers. J Am Coll Nutr 1986;3:305-12.

100. Bolton-Smith C, Casey CE, Gey KF, et al. Antioxidant vitamin intake assessed using a food-frequency questionnaire: correlation with biochemical status in smokers and nonsmokers. Br J Nutr 1991;65:337-46.

101. Harats D, Naim BM, Dabach Y, et al. Cigarette smoking renders LDL susceptible to peroxidative modification and enhanced metabolism by macrophages. Atherosclerosis 1989:79:245-52.

102. Steinberg D. Antioxidants in the prevention of human atherosclerosis. Circulation 1992;85:2337-44.

103. Jacob RA. Vitamin C. In: Shils ME, Olson JA, Shike M, eds. Modern nutrition in health and disease. Philadelphia: Lea \& Febiger, 1994:432-48.

104. National Research Council. Recommended dietary allowances, 10th ed. Washington, DC: National Academy of the Sciences, 1989

105. Iyengar $\mathrm{V}$, Woittiez J. Trace elements in human clinical specimens: evaluation of literature data to identify reference values. Clin Chem 1988;34:474-81. 